\title{
Maximum Power Point Tracking Interleaved Boost Converter Using Cuckoo Search Algorithm on The Nano Grid System
}

\author{
Taufik Hidayat \\ Department of Electrical Engineering \\ Politeknik Elektronika Negeri Surabaya \\ Surabaya, Indonesia \\ fikdayat72@pe.student.pens.ac.id
}

\author{
Mohammad Zaenal Efendi \\ Department of Electrical Engineering \\ Politeknik Elektronika Negeri Surabaya \\ Surabaya, Indonesia \\ zen@pens.ac.id
}

\author{
Farid Dwi Murdianto \\ Department of Electrical Engineering \\ Politeknik Elektronika Negeri Surabaya \\ Surabaya, Indonesia \\ farid@pens.ac.id
}

\begin{abstract}
The problems of using solar panels include the power and efficiency that can be achieved by solar panels during conditions where the surface of the solar panel is covered by shadows, because the performance of the solar panels is affected by the amount of sunlight received and the temperature of the solar panels. Then, a solution appears to overcome the problem, called Maximum Power Point Tracking or a technique to get the maximum output power from solar panels. Initially, MPPT worked with conventional methods, one of which was Perturb and Observe. Furthermore, the MPPT method on solar panels continues to develop to solve problems during partial shade conditions. The development of this conventional method is called the metaheuristic method, an example of which is the Cuckoo Search Algorithm method implemented in this research. This method is characterized by the Levy Flight equation in generating duty cycle values so that it can reach the maximum peak power of solar panels. The system built in this research is also supported by the highly efficient Interleaved Boost converter. Based on simulation results show that the power that can be generated by the MPPT Cuckoo Search Algorithm is higher than the MPPT Perturb and Observe, which is $121.23 \mathrm{~W}$ compared to $72.38 \mathrm{~W}$.
\end{abstract}

Keywords-nourishing system, watering system, RTC, humidity sensor YL-69, microcontroller, mint leaves, automatic

\section{INTRODUCTION}

At present, MPPT has been widely used with various methods and algorithms. We know some conventional methods namely Perturb and Observe (P\&O), Hill Climbing, and Incremental Conductance. The advantage is it can produce smaller oscillation if the step change value is set to small, but it would take a long time for the iteration process when tracking the maximum power value.

In addition, inactive partial shading can generate maximum power, but if on the otherwise it is stuck at the optimum local value. Partial shading is the condition of some solar panels covered by the shadow of objects (trees, clouds, etc.) so that the solar radiation received by the solar panels is not optimal, resulting in non-uniform peak power values or shadow peaks, tracking maximum power values becomes difficult, and get stuck at non-maximum power values or optimal local values. Then, a modern method emerged with the characteristic of scrambling the duty cycle value with a certain pattern in order to get the best maximum power value with few iterations and stuck in the optimum local value during partial shading conditions.[1] One of these modern methods is Cuckoo Search Algorithm (CSA) which is simulated in this study.

For designing and simulating Maximum Power Point Tracking (MPPT) control in an effort to obtain maximum power value from solar panel during shadeless (exposed) or partial shading condition by shadow. This research, Cuckoo
Search Algorithm also applied to convert duty cycle value on Interleaved Boost Converter.

\section{MEthodS}

A method used in this research will be explained at the following below:

\section{A. Modelling and Characteristics System}

\section{1) Spesifications of PV Module}

The electrical properties of photovoltaics in producing electrical energy are in accordance with the electrical characteristics of a cell which is usually described by its terminal voltage and current curves. This curve is characterized by three main points, namely the short circuit current $\left(\mathrm{I}_{\mathrm{sc}}\right)$, the open circuit voltage $\left(\mathrm{V}_{\mathrm{oc}}\right)$, and the maximum power point $\left(\mathrm{P}_{\mathrm{m}}\right)$. When a part of the photovoltaic $(\mathrm{PV})$ is exposed to shades or does not get enough amount of sunlight it results in a reduce of power. The shaded photovoltaic is operate in reverse bias operation and acts as a load instead of a source. This results in localized power dissipation and the local heat generated will cause permanent damage to the shaded photovoltaic. There are two kinds of conditions for the PV being shaded, namely: The Non-Uniform Insolation condition and the Partial Shading condition.[2]

In this research, 2 panels of $70 \mathrm{WP}$ solar panels in series are used to supply the load of four $12 \mathrm{~V} 7 \mathrm{Ah}$ batteries. The specifications of the solar panels used are according to table 1 .

TABLE I. SOlar PANEL SPESIFICATIONS

\begin{tabular}{|l|c|}
\hline \multicolumn{2}{|c|}{ Caltech Solar Panel - Poly Crystalline Solar Module } \\
\hline \multicolumn{2}{|c|}{ Performance Under Standard Test Condition $(\mathrm{STC})$} \\
\hline Maximum power $\left(\mathrm{P}_{\max }\right)$ & $80 \mathrm{~W}$ \\
\hline Minimum power $\left(\mathrm{P}_{\max }\right)$ & $72 \mathrm{~W}$ \\
\hline Maximum power current $\left(\mathrm{I}_{\mathrm{mp}}\right)$ & $4.67 \mathrm{~A}$ \\
\hline Maximum power voltage $\left(\mathrm{V}_{\mathrm{mp}}\right)$ & $17,1 \mathrm{~V}$ \\
\hline Open circuit voltage $\left(\mathrm{V}_{\mathrm{oc}}\right)$ & $21,3 \mathrm{~V}$ \\
\hline Short circuit current $\left(\mathrm{I}_{\mathrm{sc}}\right)$ & $5,3 \mathrm{~A}$ \\
\hline \multicolumn{2}{|c|}{ STC: $1000 \mathrm{~W} / \mathrm{m}^{2} ; 25^{\circ} \mathrm{C}$} \\
\hline
\end{tabular}

\section{2) Parameter of Interleaved Boost Converter}

The Interleaved Boost Converter circuit is the same as the parallel Boost Converter circuit, consisting of two pairs of switches, diodes, and inductors connected to the same filter capacitor and load.[3] Switches S1 and S2 work with a phase difference of $180^{\circ}$, resulting in an inductor current which also has a phase difference of $180^{\circ}$.[4] The current flowing from the source is the sum of the currents flowing in each inductor. The 
source current has a smaller ripple value and twice the current frequency of each inductor, so the capacitor value for the filter is smaller with the same voltage ripple value.[5]

Understand the flow of the Interleaved Boost Converter system working. The input of the IBC power supply is from the solar panel, the minimum voltage of the converter must be determined. In its application, the use of the minimum voltage can be $0 \mathrm{~V}$ because whatever energy released by the solar panel must be converted to the load even though the target power is not met, but considering the ability of the converter, the smaller the minimum voltage will be open circuit, the duty cycle is above ideal $=>80 \%$ and the large inductor value. So, to determine the minimum voltage in this research, after knowing the maximum output power of the converter, then looking at the tracking data manually with a shear resistor, it can be designed as Table 2 .

TABLE II. PARAMETERS OF INTERLEAVED BOOST CONVERTER

\begin{tabular}{|l|c|}
\hline \multicolumn{1}{|c|}{ Parameter } & Value \\
\hline Inductor & $346.83 \mu \mathrm{H}$ \\
\hline Capacitor & $180.13 \mu \mathrm{F}$ \\
\hline Resistor & $1718.99 \Omega$ \\
\hline Switching frequency & $100 \mathrm{kHz}$ \\
\hline
\end{tabular}

3) Block Diagram System

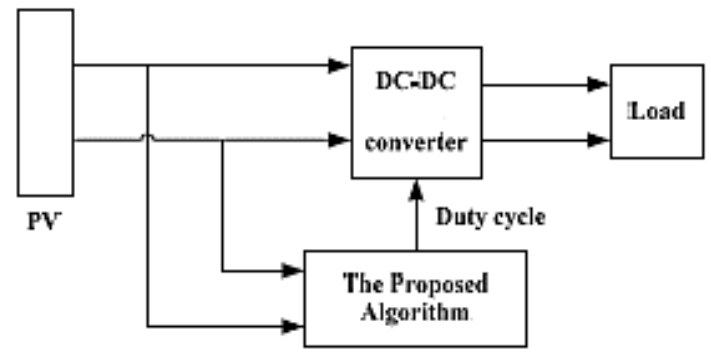

Fig. 1. Block diagram system

Fig. 1 is a block diagram of this research system. Based on the block, it can be understood that the system gets energy sources from two solar panels with a capacity of $80 \mathrm{WP}$ in series. Then, Interleaved Boost Converter works as an MPPT converter. The input of the Interleaved Boost Converter comes from the output voltage of the solar panel which tends to vary with overtime. The value of the voltage and current on the load depends on the conditions of the MPPT operating point. The Cuckoo Search Algorithm in the MPPT program will search for the maximum V-I operating point, find the GMPP area quickly, and avoid the local optimum area. Before the converter, there is an ACS712 current sensor and a voltage sensor to obtain solar panel output data. After the converter, there is also an ACS712 current sensor and a voltage sensor to monitor the converter output voltage and current values. The use of current sensors and voltage sensors aims to obtain solar panel power data which will be used as feedback to the microcontroller to run the MPPT algorithm.

Then the microcontroller will adjust the duty cycle value of the PWM so that the solar panels work at their maximum V-I operating point. Then all tracking results are saved to the SD card in real time as long as this tool works to get the data base, and all system data will be interfaced and monitored on the LCD. The method implemented in this research is the
Cuckoo Search Algorithm where the process starts from tracking until it reaches a predetermined iteration.

Then, the duty cycle value will be used as the initial value to restart the algorithm. Furthermore, if the power change value in the algorithm is less than the predetermined value, the system will lock the duty cycle value to avoid oscillation. The duty cycle will remain locked until there is a change in power that exceeds the predetermined limit. The load used is four series of $12 \mathrm{~V} 7 \mathrm{Ah}$ batteries. ARM STM32F microcontroller as a data processing tool, home to the MPPT algorithm, PWM controller for converters and monitoring because ARM is equipped with an LCD. Then, there is a PWM driver circuit before ARM to drive the PWM signal into the converter. The dual PWM contained in the converter works in two modes or alternates with an $180^{\circ}$ phase shift angle setting between the two.

\section{B. The Proposed Algorithm}

\section{1) Perturb and Observe}

The Perturb and Observe (P\&O) algorithm is very cheap and easy to implement MPPT method. The MPPT design requires two parameters to determine the slope, namely the input voltage $\left(\mathrm{V}_{\text {in }}\right)$ and the input current $\left(\mathrm{I}_{\text {in }}\right)$.

$$
\left(\mathrm{P}_{\mathrm{i} n}\right)=\left(\mathrm{V}_{\mathrm{in}}\right) \mathrm{x}\left(\mathrm{I}_{\mathrm{i} n}\right)
$$

From these two parameters, the power $\left(\mathrm{P}_{\text {in }}\right)$ and voltage $\left(\mathrm{V}_{\text {in }}\right)$ are obtained, then it is compared with the previous data reading parameters, namely $\mathrm{P}_{\mathrm{in}(\mathrm{n}-1)} \& \mathrm{~V}_{\mathrm{in}(\mathrm{n}-1)}$. The comparison results obtained $\Delta \mathrm{P}$ and $\Delta \mathrm{V}$.

$$
\begin{aligned}
& \Delta V=V_{i n(n)}-V_{i n(n-1)} \\
& \Delta P=P_{i n(n)}-P_{i n(n-1)}
\end{aligned}
$$

And the result of dividing $\Delta \mathrm{P}$ and $\Delta \mathrm{V}$ is called the slope [6].

$$
\text { Slope }=\Delta \mathrm{P} / \Delta \mathrm{V}
$$

As in Fig. 2, there are 3 types of points that are in 3 positions. To the left of the $\Delta \mathrm{P} / \Delta \mathrm{V}>0$ peak, the peak of the $\Delta \mathrm{P} / \Delta \mathrm{V}=$ 0 curve, and to the right of the $\Delta \mathrm{P} / \Delta \mathrm{V}<0$ peak.

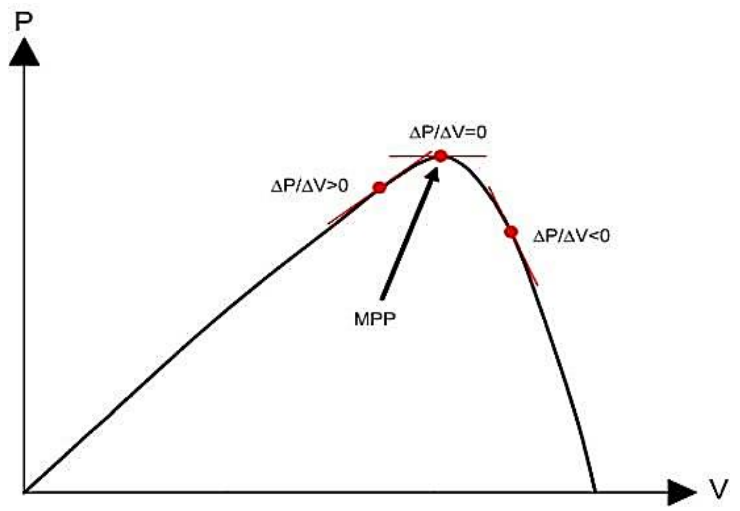

Fig. 2. Different $\Delta \mathrm{P} / \Delta \mathrm{V}$ positions on the power curve

On the left of the MPP the change in power to the voltage change $\Delta \mathrm{P} / \Delta \mathrm{V}>0$. While on the right $\Delta \mathrm{P} / \Delta \mathrm{V}<0$, it is known that perturbation is carried out to move the PV working voltage forward of the MPP control. So, the P\&O algorithm reverses the intrusion direction. The following is a fig. $3 \mathrm{P} \& \mathrm{O}$ flowchart. 


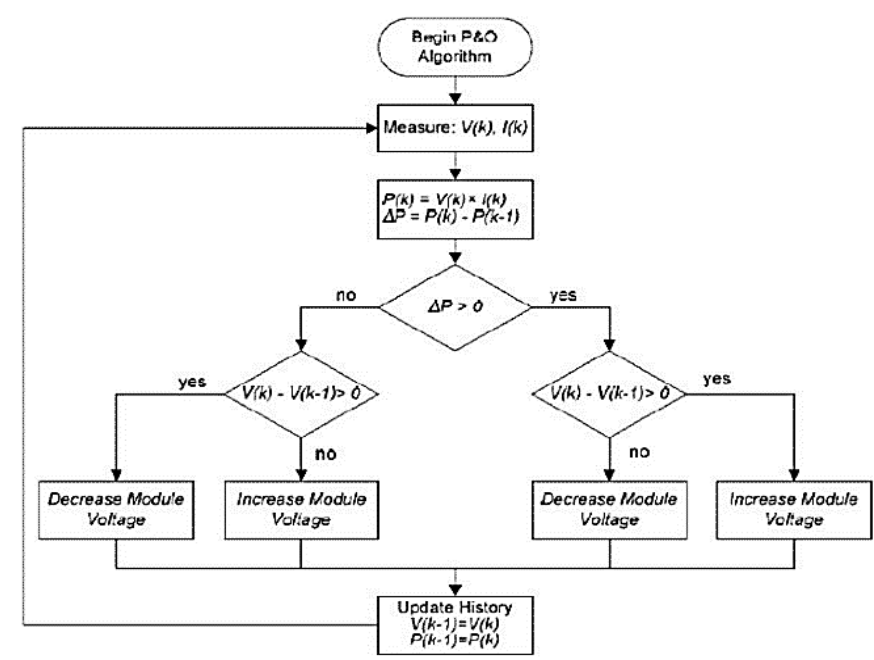

Fig. 3. Flowchart of the $\mathrm{P} \& \mathrm{O}$ algorithm

Based on Fig. 3, the P\&O algorithm flowchart when the algorithm is run the first reads of current and voltage values to calculate the power. Then, compare the previous power with the power, is it more than zero. If the difference between the previous power and the power is less than zero, then carry out the next iteration. If the difference between the voltage and the previous voltage is more than zero, then subtract the duty cycle value. If it is less than zero, then add the duty cycle. If the difference between the power and the previous power is more than zero and if the difference between the voltage and the previous voltage is greater than zero, then add the value of the duty cycle. If the difference is less than zero, then subtract the duty cycle value. Update the previous power value with the power value. The algorithm again reads the value of the PV current and voltage.[7]

The advantages of the $\mathrm{P} \& \mathrm{O}$ algorithm is easy to apply and does not require a function in seeking duty to obtain maximum power [8]. While the disadvantages of it are when partial shading occurs, the $\mathrm{P} \& \mathrm{O}$ algorithm fails its tracking duty so that it does not reach its maximum power point. Then, when it has reached a steady state, there is an oscillation around the peak point [9].

\section{Cuckoo Search Algorithm}

This algorithm mimics the behavior of the Cuckoo species, which is a parasite bird that places its eggs in another bird's nest that is not a Cuckoo species. If the parent bird finds an egg that is not from itself, then the parent bird will throw away the parasitic egg or build a new nest somewhere else. Cuckoo that successfully grows will look for another bird's nest as a place to lay eggs. The process repeats until all the cuckoo has gathered at a bird's nest. Usually three types of parent parasites are seen (1) intraspecific, (2) cooperative, and (3) takeover of nests.[10]

Some Cuckoo species, such as stripped cuckoo (Tapera naevia) is intelligent enough to mimic the shape and color of a host bird to increase its reproductive probability. After the initial hatch, Cuckoo destroys several eggs of the host bird to increase the chance of the Cuckoo child getting more food. It is also a common phenomenon that the host bird finds a Cuckoo egg cell and destroys it. Sometimes they leave their nest completely and go somewhere else to build a new nest [11].
Using CS to design MPPT, the appropriate variable must be chosen for the search. The first is sample, they are defined as PV voltage values, i.e. $(i=1,2, n)$. The total number of samples is defined as $\mathrm{n}$. Second is the step size, denoted by alpha. Initially, the resulting sample is applied to PV and power is set as the initial fitness value. The maximum power provided by the voltage is considered the current best sample. After that Lévy Flight is carried out, so a new voltage sample is generated[12] based on the following equation:

$$
\mathrm{V}_{\mathrm{i}}^{(\mathrm{t}+1)}=\mathrm{V}_{\mathrm{i}}^{\mathrm{t}}+\alpha \text { Levy }(\mathrm{V})
$$

where $\mathrm{a}=\mathrm{a} 0$ (vbest - vi). The simplified Lévy distribution scheme is presented as follows:

$$
\mathrm{s}=\mathrm{a}_{0}\left(\mathrm{~V}_{\text {best }}-\mathrm{V}_{\mathrm{i}}\right) \times \text { levy }(\Lambda) \sim \mathrm{K} \times\left(\frac{\mathrm{u}}{|\mathrm{v}|^{1 / \beta}}\right)\left(\mathrm{V}_{\text {best }}{ }^{-} \mathrm{V}_{\mathrm{i}}\right)
$$

The Cuckoo Search flowchart is shown in Fig. 4.

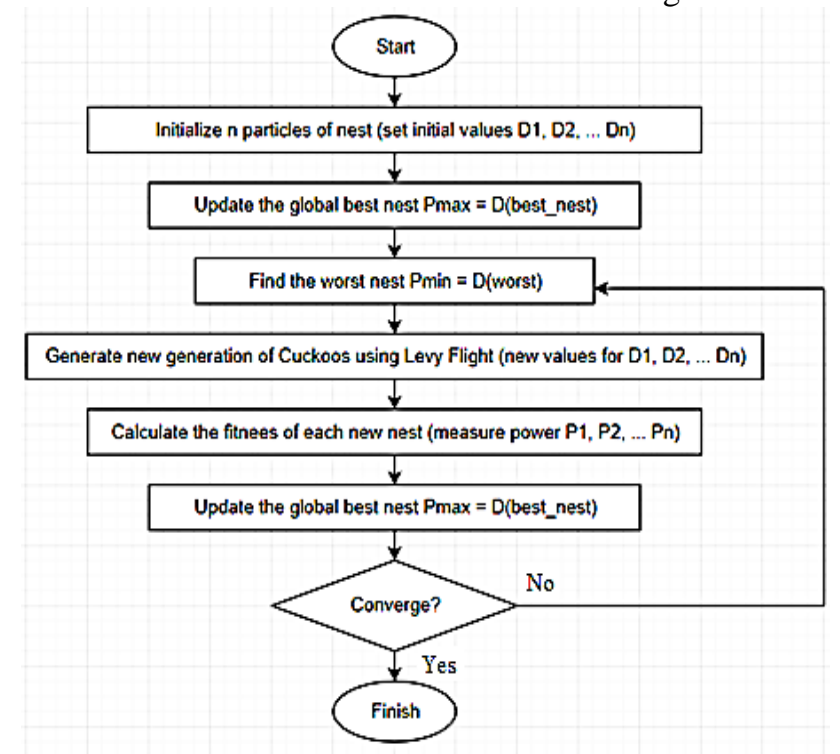

Fig. 4. Flowchart cuckoo search

To find the entire P-V curve, the initial sample must be distributed across the entire voltage range. The number of samples (n) is very important. Bigger " $n$ " increases search efficiency, which increases the chance to converge to the correct value but requires a longer convergence time. In the case of MPPT problems, extensive simulations show that $n=$ 3 is a good compromise and therefore used throughout this research.[13] The search mechanism for CS under uniform (normal) radiation is illustrated in Fig. 5. Here, the three samples are represented by variables $\mathrm{X}$ (green), $\mathrm{Y}$ (red), and Z (yellow).

The upper rank superscript of the variable shows the number of iteration numbers. For the first iteration, $\mathrm{Y}^{0}$ is located closest to MPP. Therefore, considered as the best value. Thus, $\mathrm{X}^{0}$ and $\mathrm{Z}^{0}$ are forced to move towards $\mathrm{Y}^{0}$ because the movement of the sample depends on the difference in the path between the best sample and the other sample. Furthermore, because of Lévy Flight. However, it must be noted that the random nature of CS causes the step size to vary in each iteration. As the particle moves closer to MPP, the step size gets smaller, as determined by the equation above. 


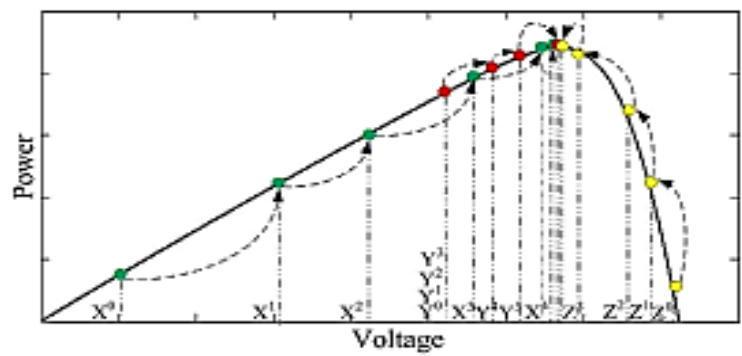

Fig. 5. MPP search mechanisms

Finally, after converging into MPP, the step size is reduced to zero. This explains that convergence in MPP has been achieved. All samples continue to be at the point of convergence. From the explanation above, there are strengths advantages and weaknesses in using the Cuckoo Search Algorithm method. The advantages of Cuckoo Search Algorithm are it can track MPP quite efficient and shows a very good convergence speed. While the weaknesses are the level of convergence is influenced by Levy Flight and may be a little slower.[14] The steps for implementing the CSA method in the MPPT application are explained as follows:

\section{a) Selecting Parameters}

In this system, Nest is defined as the duty cycle value (D) of the DC-DC converter and the fitness value is defined as the resulting $\mathrm{PV}$ output power $\left(\mathrm{P}_{\mathrm{PV}}\right)$. A higher number of duty can make optimum global power tracking more accurate.

\section{b) Initializing the CSA Method}

In this phase, the duty can be placed in a fixed or random position. Basically, if there is information about the location of the GMPP, it is better to initialize the duty in the surrounding area. This research uses 5 duty cycles.

\section{c) Fitness evaluation}

The purpose of MPPT is to maximize the power generated by PV. PWM is fired into the DC-DC converter according to the specified duty position (i). VPV and IPV can be measured using sensors then can be used to calculate the $P_{P V}$ of each duty(i) fired.

\section{d) Pbest and Newnest Update Process}

If the power value for nest (n) is better than the previous best power by nest (n), then the current value is the new Pbest (i) value. After that, select the Nest with the best power among the 5 duty cycles fired as a value.

\section{e) Update the Speed and Position of each Duty Cycle}

After all duty are evaluated, the speed and position of the duty must be updated. In the standard CSA method, the update is performed using the following equation:

$\begin{array}{ll}\text { stepsize } & =0.8 *(\text { Dbest }- \text { nest }[n]) \\ \text { newnest }[\mathrm{n}] & =\text { nest }[\mathrm{n}]+\text { stepsize }\end{array}$

The information of it are stepsize means step size in finding a position, dbest is the best duty, newnest is new duty, and nest means old duty.

\section{f) Convergence Situation}

The state of convergence is achieved if the first to fifth duty values have almost the same value. The CS algorithm will stop, and the best duty cycle output will immediately be fired at the DC-DC converter [15].

\section{Simulation Results and Discussion}

To validate the performance of proposed algorithm, PSIM model is developed to simulation studies. The block diagram to track the MPP is shown in Fig. 6 and Table 3. Based on Table 3, the test was carried out with seven solar irradiation conditions, namely, $944 \mathrm{~W} / \mathrm{m}^{2}$ and $625 \mathrm{~W} / \mathrm{m}^{2}, 900 \mathrm{~W} / \mathrm{m}^{2}$ and $680 \mathrm{~W} / \mathrm{m}^{2}, 954 \mathrm{~W} / \mathrm{m}^{2}$ and $686 \mathrm{~W} / \mathrm{m}^{2}, 927 \mathrm{~W} / \mathrm{m}^{2}$ and 751 $\mathrm{W} / \mathrm{m}^{2}, 918.8 \mathrm{~W} / \mathrm{m}^{2}$ and $778 \mathrm{~W} / \mathrm{m}^{2}, 929.5 \mathrm{~W} / \mathrm{m}^{2}$ and 502 $\mathrm{W} / \mathrm{m}^{2}, 933 \mathrm{~W} / \mathrm{m}^{2}$ and $495 \mathrm{~W} / \mathrm{m}^{2}$. The maximum power test for partial shading solar panel conditions is carried out with erratic solar irradiation conditions and can drop drastically. This then has an impact on the solar panels because the solar irradiation that is exposed to the solar panels is not optimal. From the seven data, it appears that the 5th MPPT test is higher in value than the other test data, because the MPPT power generated can reach $72.38 \mathrm{~W}$ for irradiation values of $933 \mathrm{~W} / \mathrm{m}^{2}$ and $495 \mathrm{~W} / \mathrm{m}^{2}$ and a duty cycle value of $66.21 \%$. From Table 3 shows the data of MPPT which has been made and implemented in this final project research can reach a power of $72.38 \mathrm{~W}$ from a solar panel with a capacity of 160 $\mathrm{W}$, so that the MPPT can achieve power with a percentage of:

$\%$ Increase in power

$=($ Power achieved / Solar panel capacity $) \times 100 \%$

$=(72.38 / 160) \times 100 \%$

$=45.24 \%$

So that MPPT can increase solar panel power by $45.24 \%$ of the total solar panel power capacity available. Fig. 6 shows changes in the duty cycle value for solar irradiation values of $933 \mathrm{~W} / \mathrm{m}^{2}$ and $495 \mathrm{~W} / \mathrm{m}^{2}$. The duty cycle value is processed according to the Perturb and Observe $(\mathrm{P} \& \mathrm{O})$ program. From the tests conducted, it was found that the duty cycle value was $66.21 \%$ with a simulation time of 0.2 seconds. As a result of the change in the value of the duty cycle, the value of voltage, current, and power varies, to produce the maximum power value from the solar panel. Sometimes the change in the duty cycle value is random or allows a very drastic change in the duty cycle value. Fig. 6 shows changes in the duty cycle value for solar irradiation values of $933 \mathrm{~W} / \mathrm{m}^{2}$ and $495 \mathrm{~W} / \mathrm{m}^{2}$ as well as the values of currents, voltages, and power obtained.
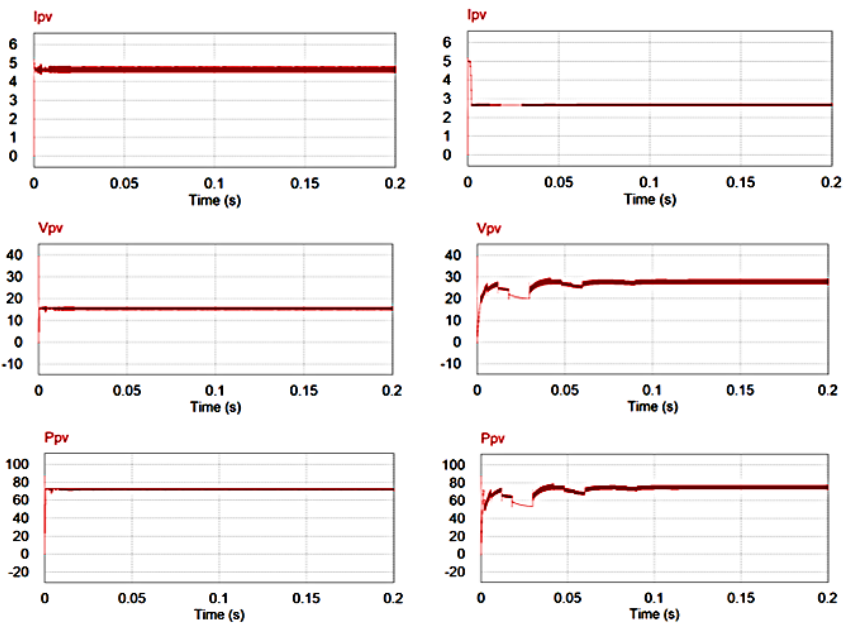

Fig 6. Value of current, voltage and power when irradiated $933 \mathrm{~W} / \mathrm{m}^{2}$ from the P\&O (Left) and CSA (Right) 
TABLE III. POWER COMPARISON OF P\&O AND CSA METHODS

\begin{tabular}{|c|c|c|c|c|c|c|c|}
\hline Irad1 & T1 & Irad2 & T2 & \multicolumn{2}{|c|}{ P\&O } & \multicolumn{2}{|c|}{ CSA } \\
\cline { 5 - 8 }$\left(\mathrm{W} / \mathrm{m}^{2}\right)$ & $\left({ }^{\circ} \mathrm{C}\right)$ & $\left(\mathrm{W} / \mathrm{m}^{2}\right)$ & $\left({ }^{\circ} \mathrm{C}\right)$ & $\mathrm{D}(\%)$ & $\mathrm{P}_{\mathrm{Ea}}(\mathrm{W})$ & $\mathrm{D}(\%)$ & $\mathrm{P}_{\mathrm{Ea}}(\mathrm{W})$ \\
\hline 944 & 63 & 625 & 57 & 68,11 & 66,5 & 43,97 & 97 \\
\hline 900 & 63,6 & 680 & 37,6 & 67,39 & 63,2 & 44,64 & 107,92 \\
\hline 954 & 67,2 & 686 & 42,2 & 68,69 & 65,63 & 45,09 & 107,63 \\
\hline 927 & 65 & 751 & 50 & 68,1 & 64,61 & 48,43 & 114,94 \\
\hline 918,8 & 51,5 & 778 & 41,1 & 66,77 & 68,62 & 48,1 & 124,56 \\
\hline 929,5 & 47,7 & 502 & 38,5 & 66,61 & 70,71 & 41,16 & 74,53 \\
\hline 933 & 43,8 & 495 & 38,38 & 66,21 & 72,38 & 41,16 & 72,58 \\
\hline
\end{tabular}

Fig. 6 shows a change in the value of the solar panel voltage, the value of the voltage continues to change according to the change in the duty cycle value. Fig. 6 also shows the changes in voltage values for solar irradiation values of $933 \mathrm{~W} / \mathrm{m}^{2}$ and $495 \mathrm{~W} / \mathrm{m}^{2}$. It can be seen in the wave that, the voltage value changes continuously until the duty cycle value converges, and a voltage of around 15.55 volts is obtained and this voltage is the voltage at the maximum power value. There is also information on the current value from the solar panel or the current entering the converter. The current value continues to change according to the changes in the duty cycle value. It can be seen that the resulting current has a current value for maximum power during the tracking process, so that the power value generated by the MPPT is $72.38 \mathrm{~W}$ with a voltage value of 15.55 Volts and a current value of $4.66 \mathrm{~A}$. Figure 4 also shows the power from the solar panels for irradiation values of $933 \mathrm{~W} / \mathrm{m}^{2}$ and $495 \mathrm{~W} / \mathrm{m}^{2}$. The change in power that occurs depends on the duty cycle value generated in the program and it also affects changes in the value of the current and voltage generated by the solar panel, so that the value of the power generated by the solar panel also changes. When the duty cycle value has converged, so that the duty cycle value is obtained for the maximum power value from the solar panel.

From Table 3, the maximum power of the solar panels for partial shading conditions occurs at various duty cycle values according to the irradiation value and temperature. Tests are carried out using PSIM software and the maximum power that a solar panel can produce is $160 \mathrm{~W}$ in series. It was explained that for the MPPT test with partial shading conditions it was carried out with several variations in solar irradiation values, with irradiation values of $944 \mathrm{~W} / \mathrm{m}^{2}$ and $625 \mathrm{~W} / \mathrm{m}^{2}, 900 \mathrm{~W} / \mathrm{m}^{2}$ and $680 \mathrm{~W} / \mathrm{m}^{2}, 954 \mathrm{~W} / \mathrm{m}^{2}$ and $686 \mathrm{~W} / \mathrm{m}^{2}, 927 \mathrm{~W} / \mathrm{m}^{2}$ and 751 $\mathrm{W} / \mathrm{m}^{2}, 918.8 \mathrm{~W} / \mathrm{m}^{2}$ and $778 \mathrm{~W} / \mathrm{m}^{2}, 929.5 \mathrm{~W} / \mathrm{m}^{2}$ and 502 $\mathrm{W} / \mathrm{m}^{2}, 933 \mathrm{~W} / \mathrm{m}^{2}$ and $495 \mathrm{~W} / \mathrm{m}^{2}$. Table 3 also shows the temperature values that occur in solar panels, this can also affect the output power of the solar panels. For irradiation of $918.8 \mathrm{~W} / \mathrm{m}^{2}$ and $778 \mathrm{~W} / \mathrm{m}^{2}$, the duty cycle is $48.1 \%$. The value of duty cycle, current, voltage, and power produced is as shown in Fig. 7.
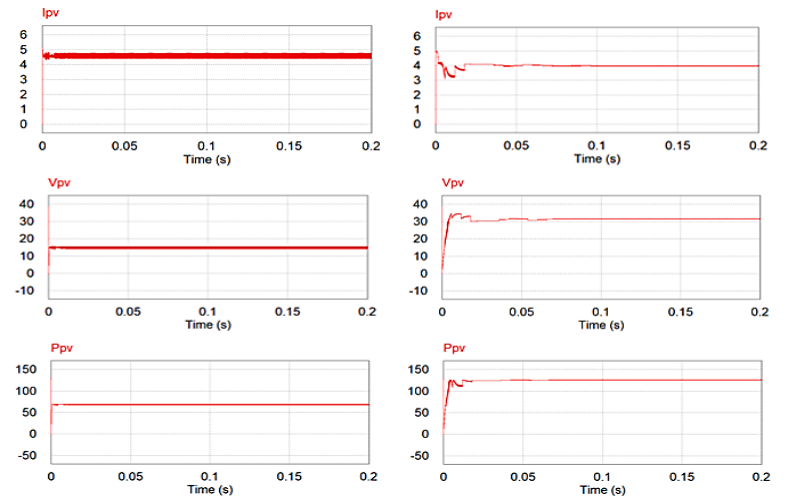

Fig. 7. Value of current, voltage and power when irradiated $918.8 \mathrm{~W} / \mathrm{m}^{2} \&$ $778 \mathrm{~W} / \mathrm{m}^{2}$ from the P\&O (left) and CSA (right)
Fig. 7 describes the change in the voltage value of the solar panel. It can be seen from the graph that the voltage value changes continuously until the duty cycle value converges, the voltage value during the solar panel is in partial shading can also affect the value of the power generated by the solar panel. When the duty cycle value converges, the resulting voltage value ranges from 31.35 volts, and this value is the voltage value for the maximum power of the solar panel during partial shading conditions. Fig. 7 also explains the value of the electric current generated by the solar panel, it can be seen that the current value continues to change until the duty cycle value reaches a convergent value, and when the duty cycle value converges, the current value is the current value generated when the solar panel reaches at maximum power value.

In addition, there is information on changes in the power value generated by MPPT during searching for the maximum power value of solar panels. The change in the resulting power value is not large, because the displacement of the duty cycle value from the algorithm is not too large. The randomized duty cycle value takes time to determine the maximum power value of the solar panel, changes in the value of the duty cycle causes the voltage value, current value, and power value to vary. Changes in irradiation value are also very influential in the MPPT test. From Table 3 shows that the MPPT that has been created and simulated in this final project research can reach a power of $121.23 \mathrm{~W}$ from a solar panel with a capacity of $160 \mathrm{~W}$, so that the MPPT can achieve power with a percentage of:

$\%$ Increase in power

$=($ Power achieved / Solar panel capacity $) \times 100 \%$

$=(121.23 / 160) \times 100 \%$

$=77.85 \%$

The power generated by MPPT Perturb and Observe (P\&O) for battery loads produces the least power of 63.2 Watt with solar irradiation of $900 \mathrm{~W} / \mathrm{m}^{2}$ and $680 \mathrm{~W} / \mathrm{m}^{2}$ and produces the greatest power with a value of 72.38 Watt with solar irradiation of $933 \mathrm{~W} / \mathrm{m}^{2}$ and $495 \mathrm{~W} / \mathrm{m}^{2}$. From the data above, it appears that the power generated using the MPPT Perturb and Observe $(\mathrm{P \& O})$ is lower than the power generated by the MPPT Cuckoo Search Algorithm. Based on the data above, it shows that when the irradiation is $918.8 \mathrm{~W} / \mathrm{m}^{2}$ and $778 \mathrm{~W} / \mathrm{m}^{2}$ the power value generated using the MPPT Cuckoo Search Algorithm is $121.23 \mathrm{~W}$. This shows that the power that can be generated by MPPT Cuckoo Search Algorithm is higher than the power generated by MPPT Perturb and Observe (P\&O).

\section{CONCLUSION}

After going through several processes of planning, manufacturing, testing, and retrieving data obtained from this test. For partial shading conditions, MPPT Perturb and Observe can determine a maximum power of $72.38 \mathrm{~W}$ with a duty cycle value of $66.21 \%$ with an irradiation value of 933 $\mathrm{W} / \mathrm{m} 2$ and $495 \mathrm{~W} / \mathrm{m}^{2}$. For partial shading conditions, the MPPT Cuckoo Search Algorithm can determine a maximum power of $121.23 \mathrm{~W}$ with a duty cycle value of $48.1 \%$ with an irradiation value of $918.8 \mathrm{~W} / \mathrm{m} 2$ and $778 \mathrm{~W} / \mathrm{m}^{2}$. The simulation results show that the power generated by the MPPT Cuckoo Search Algorithm is higher than the power generated by the MPPT Perturb and Observe (P\&O). 


\section{ACKNOWLEDGMENT}

This research is supported by Politeknik Elektronika Negeri Surabaya.

\section{REFERENCES}

[1] Trishan Esram and Patrick L. Chapman. "Comparison of Photovoltaic Array Maximum Power Point Tracking Techniques". IEEE Transaction on Energy Conversion Vol. 22 No. 2 June 2007.

[2] Marcelo Gradella Villalva, Jonas Rafael Gazoli, and Ernesto Ruppert Filho. "Comprehensive Approach to Modeling and Simulation of Photovoltaic Arrays". IEEE Transactions on Power Electronics, Vol. 24, No. 5, May 2009.

[3] Saleh E. Babaa, Georges El Murr, Faisal Mohamed, Srilatha Pamuri. "Overview of Boost Converters for Photovoltaic Systems". Journal of Power and Energy Engineering Vol. 6 No. 4 April 2018.

[4] Haoyu Wang, Serkan Dusmez, and Alireza Khaligh. "Design and Analysis of a Full-Bridge LLC-Based PEV Charger Optimized for Wide Battery Voltage Range". IEEE Transactions on Vehicular Technology 63(4): 1603-1613 May 2014.

[5] Ganta, Mounika, etc. "Simple and Efficient Implementation of TwoPhase Interleaved Boost Converter for Renewable Energy Source". International Journal of Emerging Technology and Advanced Engineering Vol. 2 July 2017.

[6] S. Bandri, Zulkarnaini, A. Syofian, A. Effendi. "The Application of Perturb and Observe Algorithm to Optimized of Solar Cell Output". The 2018 International Conference on Research and Learning of Physics.

[7] Ahmed M. Atallah, Almoataz Y. Abdelaziz, Raihan S. Jumaah. "Implementation of Perturb and Observe MPPT of PV System with Direct Control Method using Buck and Buck-Boost Converters". Emerging Trends in Electrical, Electronics \& Instrumentation Engineering (EEIEJ) Vol. 1 No. 1 February 2014

[8] Muhammad Kamran, Muhammad Mudassar, Muhammad Rayyan Fazal, Muhammad Usman Asghar, Muhammad Bilal, Rohail Asghar. "Implementation of Improved Perturb \& Observe MPPT Technique with Confined Search Space for Standalone Photovoltaic System". Journal of King Saud University - Engineering Sciences 32 (2020).

[9] Umashankar Patel, Ms. Dhaneshwari Sahu, Deepkiran Tirkey. "Maximum Power Point Tracking using Perturb \& Observe Algorithm and Compare with Another Algorithm". International Journal of Digital Application \& Contemporary Reseacrh Vol. 2 Issue 2 September 2013

[10] Jubaer Ahmed, Zainal Salam. "A Soft Computing MPPT for PV System Based on Cuckoo Search Algorithm". Conference Paper at Conference Power Engineering, Energy and Electrical Drives (POWERENG) 2013.

[11] Mohamed I. Mosaad, M. Osama Abed el-Raouf, Mahmoud A. alAhmar, Fahd A. Banakher. "Maximum Power Point Tracking of PV System Based Cuckoo Search Algorithm: Review and Comparison”. Journal Energy Procedia 162 (2019) 117-126.

[12] Ji Ying Shi, Fei Xue, Zi Jian Qin, Wen Zhang, Le Tao Ling, and Ting Yang. "Improved Global Maximum Power Point Tracking for Photovoltaic System via Cuckoo Search under Partial Shaded Condition". Journal of Power Electronics Vol. 16 No. 1 January 2016.

[13] B. Srinivasa Rao, K. Kiran Kumar, D. Vijaya Kumar. "Design and Simulation of Hybrid System using Cuckoo MPPT Technique". International Journal of Engineering and Advanced Technology (IJEAT) Vol. 8 Issue 6 August 2019.

[14] Ahmad A. El Baset A. El Halim, Naggar H. Saad, Ahmed A. El Saffar. "A Comparative Study Between Perturb and Observe and Cuckoo Search Algorithm for Maximum Power Point Tracking”. $201921^{\text {st }}$ International Middle East Power System Conference (MEPCON) Tanta University Egypt.

[15] Dimas Aji Nugraha, K. L. Lian, Suwarno. "A Novel MPPT Method Based on Cuckoo Search Algorithm and Golden Section Search Algorithm for Partially Shaded PV System". Canadian Journal of Electrical and Computer Engineering Vol. 42 No. 3 Summer 2019. 